\title{
Weight retention within the puerperium in adolescents: a risk factor for obesity?
}

\author{
Minerva M Thame ${ }^{1, *}$, Maria D Jackson ${ }^{2}$, Inger P Manswell ${ }^{1}$, Clive Osmond ${ }^{3}$ and \\ Matthias $G$ Antoine ${ }^{1}$ \\ 'Department of Obstetrics and Gynaecology and Child Health, The University of the West Indies, Mona, \\ Kingston 7, Jamaica: ${ }^{2}$ Department of Community Health and Psychiatry, The University of the West Indies, \\ Mona, Kingston, Jamaica: ${ }^{3}$ Medical Research Council Epidemiology Resource Centre, University of \\ Southampton, Southampton General Hospital, Southampton, UK
}

Submitted 24 March 2009: Accepted 17 July 2009: First published online 1 September 2009

\begin{abstract}
Objective: The present study aimed to investigate weight retention and body composition in the postpartum period between adolescent girls and older women.

Design: A prospective cohort study. Anthropometry and skinfold thickness measurements were performed at the first antenatal visit and at 6 weeks postpartum. An FFQ was administered at 6 weeks postpartum to explore the relationship between diet and postpartum weight retention.

Setting: Clinics at the University of the West Indies, Kingston, Jamaica.

Subjects: Recruitment included women aged 19 years and younger (adolescent girls) and 20 years and older (older women).

Results: Three hundred and forty women were studied. Adolescent girls had significantly lower measurements compared with the older women at the first antenatal visit and at 6 weeks postpartum. Dietary intakes of energy and macronutrients were similar in both groups. Postnatal assessments showed that adolescent girls retained more weight $(P=0.003)$ and a greater percentage of body fat $(P<0.002)$ than older women. In multiple regression analyses, $0.982 \mathrm{~kg}$ more fat mass was retained postpartum in the adolescent group compared with the older women, while there was no significant difference in lean body mass retained between the two groups.

Conclusions: Adolescent girls retained more weight postpartum and this was predominantly fat mass as opposed to lean body mass.
\end{abstract}

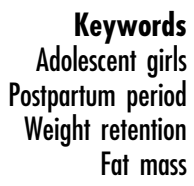

Obesity is an important risk factor for the development of chronic adult diseases such as diabetes mellitus and CHD. Pregnancy has frequently been cited as a contributor to becoming overweight. Average postpartum weight retention ranges from 0.5 to $3 \mathrm{~kg}$; however, postpartum weight retention appears to be highly variable with some women retaining as much as $17 \cdot 7 \mathrm{~kg}^{(1)}$. Factors such as pre-pregnancy weight and excessive gestational weight gain are strong risk factors for postpartum weight retention $^{(2,3)}$. Studies suggest that women with the highest gestational weight gain and body fat ( $\geq 30 \mathrm{~g}$ fat $/ 100 \mathrm{~g}$ body weight at baseline) have the highest likelihood of developing maternal obesity ${ }^{(4)}$.

Adolescent pregnancy has been associated with greater gestational weight gain and may have continued accrual of subcutaneous fat and increased risk of weight retention postpartum $^{(5)}$. The distribution of fat is also important. Studies report that with central obesity, in contrast to absolute increase in weight, there is an increased risk of overweight and obesity in later life $\mathrm{e}^{(2,5)}$.

Rossner noted that approximately 40 to $50 \%$ of female patients reported that pregnancy had been important in the development of their obesity ${ }^{(6)}$. Pregnancy has been regarded as an example of weight cycling. Weight cycling refers to initial weight loss during dieting programmes with subsequent regain after relapse. The increased weight gain during and subsequent fall after pregnancy mimic an interesting biological and 'normal' cause of such weight cycling. Behavioural and metabolic consequences of such repeated body weight cycling have generated much inter$\mathrm{est}^{(7)}$, with particular focus on repeated changes in body weight as a risk factor for CHD and mortality ${ }^{(8)}$.

Numerous studies have indicated that mean body weight and prevalence of obesity increase with each pregnancy ${ }^{(9-13)}$. Whereas confirmation of earlier findings is important, there is a need to further investigate the 
composition of the weight gained in pregnancy and the factors influencing weight gain. In the present prospective study, a cohort of adolescent girls and older women was followed from their first antenatal clinic visit to 6 weeks postpartum. Weight retention and body composition were assessed in each group. It was hypothesized that the adolescents were at a greater risk of postnatal weight retention. Specifically, it was suggested that weight gained during pregnancy would remain an important contributor to risk of weight retention after accounting for the effects of known weight-related factors such as parity, gestational age at birth and demographic variables.

\section{Experimental methods}

The University Hospital of the West Indies (UHWI), Kingston, Jamaica, is a 500-bed teaching hospital which offers services and trains undergraduate and postgraduate students in various disciplines in medicine. The Department of Obstetrics and Gynaecology conducts antenatal clinics which enrol pregnant women during the first trimester, at approximately 8 weeks' gestation. Antenatal clinics at UHWI are well developed, have been in existence for more than 50 years and provide quality care to pregnant women. The hospital records 2500 to 3000 deliveries per year.

Four hundred and twenty-five women attending their first antenatal clinic at UHWI were informed about the current prospective study, agreed to participate, and were enrolled consecutively. The study enrolled two groups of antenatal subjects: (i) females aged 19 years and younger, referred to as adolescent girls; and (ii) women aged 20 years and older, referred to as older women. Recruitment was restricted to presenting antenatal women who were less than 15 weeks pregnant at their first clinic visit, had a singleton pregnancy and did not have systemic illnesses that included hypertension, diabetes mellitus, collagen vascular disease or genetic abnormality such as sickle cell disease. Gestational age was determined by the last menstrual period and confirmed by an ultrasound measurement performed at approximately 15 weeks' gestation. Once written informed consent was obtained, a questionnaire which queried information on demographics, socio-economic status, use of substances such as cigarettes, alcohol, marijuana and cocaine, and menstrual details was administered to all subjects. A socio-economic score was calculated using education and occupation of the mother and father, household possessions and a crowding index (calculated as the number of habitable rooms in the dwelling divided by the number of people living in that dwelling). A higher score denoted better socio-economic status. All subjects were followed from the first antenatal visit to the 6-week postnatal clinic visit.

The study was approved by the Ethics Committee of the University of the West Indies and subjects gave written informed consent to participate in the study.
Maternal anthropometry was performed at the first antenatal visit and at the 6-week postnatal visit. These measurements included maternal weight, which was measured to the nearest $0 \cdot 01 \mathrm{~kg}$ using a Tanita digital scale (CMS Weighing Equipment Ltd, London UK); height to the nearest $0 \cdot 1 \mathrm{~cm}$ using a stadiometer (CMS Weighing Equipment Ltd); and biceps, triceps, suprailiac, subscapular and mid-thigh skinfold thicknesses to the nearest $0 \cdot 2 \mathrm{~mm}$ using a Holtain skinfold calliper (CMS Weighing Equipment Ltd). Blood pressure and urine analysis results were obtained from antenatal records at the first antenatal visit and at 25 and 35 weeks' gestation.

Pregnancy-induced hypertension was defined as systolic blood pressure $\geq 140 \mathrm{mmHg}$ or diastolic blood pressure $\geq 90 \mathrm{mmHg}$ after 20 weeks' gestation, in the absence of proteinuria, in mothers who were not chronically hypertensive and in whom blood pressure returned to normal by one month after delivery ${ }^{(14)}$. Preeclampsia was defined by the same blood pressure criteria but with proteinuria. Proteinuria was defined by dipstick as greater than or equal to $1+$ proteinuria.

At the 6-week postnatal visit, the infant's weight was measured to the nearest $0 \cdot 01 \mathrm{~kg}$ using a Tanita model 1583 digital baby scale (CMS Weighing Equipment Ltd) and crown-heel length was measured to the nearest $0 \cdot 1 \mathrm{~cm}$ using a Harpenden infantometer (CMS Weighing Equipment Ltd). Head, chest, abdominal and mid-upper arm circumferences were measured using a fibreglass tape measure, and biceps, triceps, subscapular and suprailiac skinfold thicknesses were also measured to the nearest $0.2 \mathrm{~mm}$ using a Holtain skinfold caliper (CMS Weighing Equipment Ltd). Breast-feeding practices were ascertained from the participants at the postnatal visit.

The contribution of diet was examined on a convenience sample of sixty older women and sixty adolescents at 6 weeks postpartum to determine habitual dietary intake. Habitual dietary intakes were obtained by a previously validated FFQ for the adult Jamaican population $^{(15)}$. Interviewers were equipped with food models and household utensils to help participants quantify the food and beverages consumed.

Measurements were done on ten subjects prior to commencement of the study to assess the reliability of measurements within and between the two trained interviewers who performed all measurements for the study.

\section{Statistical analyses}

Data are expressed as means and standard deviations. Calculations to establish fat mass and fat-free mass or lean body mass were performed using standard equations ${ }^{(16,17)}$. Using the independent Student's $t$ test, differences between the two groups were identified. Multiple linear regression analyses were used to ascertain the extent to which sociodemographic and reproductive factors contributed to weight retention in the adolescent girls and older women. Statistical analyses were performed 
using the SPSS statistical software package version $11 \cdot 0$ (SPSS Inc., Chicago, IL, USA). Statistical significance was achieved when $P<0 \cdot 05$.

\section{Results}

Of the 425 participants, 361 (84.9\%) subjects delivered at UHWI. Forty-three $(10 \cdot 1 \%)$ had early pregnancy losses; seventeen $(4 \cdot 0 \%)$ defaulted from the study for various reasons (migration, attended other antenatal clinics due to cost); there were two twin pregnancies $(0.5 \%)$, both occurring in the adolescent group; and two (0.5\%) women booked later than 15 weeks' gestation as confirmed by an early ultrasound. Ninety-four per cent (340/361) of subjects who gave birth at the hospital had a 6-week postnatal visit. There was one neonatal death; and one neonate who was still admitted to the Special Care Nursery at the time of the 6-week postnatal visit for stage III hypoxic ischaemic encephalopathy. Nineteen mothers were not measured due to changes made in the date of their visits to the postnatal clinic. Antenatal clinic attendance was high in both groups (greater than $96 \%$ of clinic visits), with each group recording eight or nine visits throughout the study.

Maternal characteristics of the adolescent girls and older women at the first antenatal visit are shown in Table 1. One hundred and sixty-five women less than 20 years comprised the adolescent group and 175 women 20 years or older were enrolled as the older group. Age at menarche and interval between menarche and pregnancy were significantly lower in the adolescent group than in the older women. Adolescent girls when compared with their older counterparts had lower mean socio-economic scores, thereby suggesting that they had a lower socioeconomic status (Table 1).
At the first antenatal visit, adolescent girls had significantly lower anthropometric measurements than older women (Table 1). Older women were heavier and had larger skinfold thicknesses than the adolescents. Fat mass and lean body mass were examined in both groups, and adolescent girls had significantly lower fat mass and lean body mass at the first antenatal visit.

At the 6-week postnatal visit significant differences in anthropometry and skinfold thickness between the adolescent girls and the older women were seen, and also the fat mass and lean mass were significantly lower in the adolescents compared with the older women (Table 2).

The differences in weight, skinfold thicknesses, fat mass and lean body mass at the first antenatal visit and the 6-week postnatal visit were examined between the adolescent girls and the older woman. Despite having smaller measurements antenatally and postnatally, the adolescent girls retained more weight, percentage fat and fat mass than the older women postpartum. There was no difference seen in lean body mass (Table 3).

Substance use during pregnancy among adolescent girls and older women was low and was not significantly different between the groups (cigarette smoking, 3.6\% v. $2 \cdot 3 \%$; alcohol intake, $9 \cdot 7 \%$ v. $8 \cdot 7 \%$; marijuana, $4 \cdot 2 \%$ v. $1 \cdot 1 \%$, respectively). Neither adolescent girls nor older women reported using cocaine.

Multiple regression analyses controlling for socioeconomic status, gestational age at birth and age at menarche showed that adolescent girls retained significantly greater fat mass $(0.982 \mathrm{~kg}$ more $)$ postpartum than the older women. There was no significant difference in the lean body mass retained in the two groups.

Dietary assessments revealed that intakes of energy and macronutrients were similar in both groups (data not shown). Among adolescent girls the mean daily energy

Table 1 Maternal characteristics at the first antenatal visit: women aged 19 years and younger (adolescent girls) and 20 years and older (older women) attending clinics at the University of the West Indies, Kingston, Jamaica

\begin{tabular}{|c|c|c|c|c|c|}
\hline \multirow[b]{2}{*}{ Variable } & \multicolumn{2}{|c|}{ Adolescent girls ( $n$ 165) } & \multicolumn{2}{|c|}{ Older women $(n 175)$} & \multirow[b]{2}{*}{$P$} \\
\hline & Mean & SD & Mean & SD & \\
\hline Age at menarche (years) & $12 \cdot 5$ & $1 \cdot 3$ & $13 \cdot 1$ & $1 \cdot 6$ & $<0.0001$ \\
\hline Gestational age (weeks) & $10 \cdot 7$ & $1 \cdot 8$ & $9 \cdot 9$ & $1 \cdot 5$ & $<0.0001$ \\
\hline Parity & 0.3 & 0.5 & $1 \cdot 3$ & $1 \cdot 3$ & 0.01 \\
\hline Socio-economic score & $44 \cdot 6$ & $4 \cdot 4$ & $48 \cdot 9$ & $3 \cdot 4$ & $<0.0001$ \\
\hline Age (years) & $17 \cdot 7$ & $1 \cdot 3$ & $28 \cdot 3$ & $5 \cdot 4$ & $<0.0001$ \\
\hline Weight (kg) & $60 \cdot 3$ & $12 \cdot 4$ & $69 \cdot 3$ & $13 \cdot 9$ & $<0.0001$ \\
\hline Height $(\mathrm{cm})$ & $162 \cdot 8$ & $5 \cdot 8$ & $164 \cdot 0$ & $5 \cdot 6$ & 0.054 \\
\hline BMI $\left(\mathrm{kg} / \mathrm{m}^{2}\right)$ & $22 \cdot 7$ & $4 \cdot 3$ & $25 \cdot 7$ & $4 \cdot 8$ & $<0.0001$ \\
\hline Mid-upper arm circumference $(\mathrm{cm})$ & $26 \cdot 6$ & $3 \cdot 8$ & $29 \cdot 7$ & $4 \cdot 2$ & $<0.0001$ \\
\hline \multicolumn{6}{|l|}{ Skinfold thickness (mm) } \\
\hline Biceps & $7 \cdot 8$ & $4 \cdot 1$ & $10 \cdot 0$ & $5 \cdot 1$ & $<0.0001$ \\
\hline Triceps & $14 \cdot 9$ & $5 \cdot 6$ & $19 \cdot 6$ & $7 \cdot 2$ & $<0.0001$ \\
\hline Suprailiac & $14 \cdot 4$ & $6 \cdot 5$ & $17 \cdot 9$ & $7 \cdot 5$ & $<0.0001$ \\
\hline Subscapular & $15 \cdot 5$ & 6.9 & $22 \cdot 1$ & $9 \cdot 1$ & $<0.0001$ \\
\hline Mid-thigh & $24 \cdot 8$ & $8 \cdot 1$ & $31 \cdot 0$ & $8 \cdot 8$ & $<0.0001$ \\
\hline Percentage fat (\%) & $25 \cdot 8$ & $5 \cdot 1$ & $30 \cdot 9$ & $5 \cdot 8$ & $<0.0001$ \\
\hline Fat mass $(\mathrm{kg})$ & $16 \cdot 1$ & $6 \cdot 5$ & $22 \cdot 0$ & $7 \cdot 8$ & $<0.0001$ \\
\hline Lean body mass $(\mathrm{kg})$ & $44 \cdot 2$ & $6 \cdot 4$ & $47 \cdot 1$ & $6 \cdot 5$ & $<0.0001$ \\
\hline
\end{tabular}


Table 2 Maternal characteristics at the 6-week postpartum visit: women aged 19 years and younger (adolescent girls) and 20 years and older (older women) attending clinics at the University of the West Indies, Kingston, Jamaica

\begin{tabular}{|c|c|c|c|c|c|}
\hline \multirow[b]{2}{*}{ Variable } & \multicolumn{2}{|c|}{ Adolescent girls ( $n$ 165) } & \multicolumn{2}{|c|}{ Older women (n 175) } & \multirow[b]{2}{*}{$P$} \\
\hline & Mean & SD & Mean & SD & \\
\hline Weight (kg) & $63 \cdot 5$ & $12 \cdot 7$ & $71 \cdot 1$ & $13 \cdot 1$ & $<0.0001$ \\
\hline Height (cm) & $162 \cdot 6$ & $5 \cdot 8$ & $163 \cdot 9$ & $5 \cdot 6$ & 0.04 \\
\hline BMI $\left(\mathrm{kg} / \mathrm{m}^{2}\right)$ & $24 \cdot 0$ & $4 \cdot 4$ & $26 \cdot 4$ & 4.5 & $<0.0001$ \\
\hline Mid-upper arm circumference $(\mathrm{cm})$ & $27 \cdot 0$ & $3 \cdot 7$ & $29 \cdot 4$ & 3.9 & $<0.0001$ \\
\hline \multicolumn{6}{|l|}{ Skinfold thickness (mm) } \\
\hline Biceps & $7 \cdot 8$ & $3 \cdot 6$ & $8 \cdot 8$ & $4 \cdot 2$ & 0.03 \\
\hline Triceps & $15 \cdot 2$ & $5 \cdot 4$ & $18 \cdot 8$ & $6 \cdot 2$ & $<0.0001$ \\
\hline Suprailiac & $15 \cdot 0$ & $6 \cdot 7$ & $18 \cdot 4$ & $6 \cdot 9$ & $<0.0001$ \\
\hline Subscapular & $16 \cdot 5$ & $6 \cdot 7$ & $20 \cdot 8$ & $7 \cdot 4$ & $<0.0001$ \\
\hline Mid-thigh & $26 \cdot 7$ & $8 \cdot 1$ & $31 \cdot 8$ & $8 \cdot 1$ & $<0.0001$ \\
\hline Percentage fat (\%) & $26 \cdot 4$ & $5 \cdot 0$ & $30 \cdot 7$ & 4.9 & $<0.0001$ \\
\hline Fat mass $(\mathrm{kg})$ & $17 \cdot 2$ & $6 \cdot 5$ & $22 \cdot 2$ & $7 \cdot 2$ & $<0.0001$ \\
\hline Lean body mass (kg) & $45 \cdot 9$ & $6 \cdot 7$ & $48 \cdot 7$ & $6 \cdot 8$ & $<0.0001$ \\
\hline
\end{tabular}

Table 3 Change in maternal characteristics between the first antenatal visit and the 6-week postnatal visit: women aged 19 years and younger (adolescent girls) and 20 years and older (older women) attending clinics at the University of the West Indies, Kingston, Jamaica

\begin{tabular}{|c|c|c|c|c|c|}
\hline \multirow[b]{2}{*}{ Variable } & \multicolumn{2}{|c|}{ Adolescent girls ( $n$ 165) } & \multicolumn{2}{|c|}{ Older women ( $n$ 175) } & \multirow[b]{2}{*}{$P$} \\
\hline & Mean & SD & Mean & $\mathrm{SD}$ & \\
\hline Weight (kg) & $3 \cdot 1$ & $4 \cdot 2$ & $1 \cdot 7$ & $4 \cdot 3$ & 0.003 \\
\hline Height (cm) & $-0 \cdot 2$ & $0 \cdot 1$ & $-0 \cdot 3$ & 0.6 & 0.692 \\
\hline BMI $\left(\mathrm{kg} / \mathrm{m}^{2}\right)$ & $1 \cdot 3$ & $1 \cdot 6$ & 0.7 & $1 \cdot 6$ & 0.001 \\
\hline Mid-upper arm circumference $(\mathrm{cm})$ & 0.4 & $1 \cdot 3$ & $-0 \cdot 3$ & 1.5 & $<0.0001$ \\
\hline \multicolumn{6}{|l|}{ Skinfold thickness (mm) } \\
\hline Biceps & -0.02 & $2 \cdot 4$ & $-1 \cdot 2$ & $3 \cdot 3$ & $<0.0001$ \\
\hline Triceps & 0.5 & $2 \cdot 9$ & -0.7 & $4 \cdot 1$ & 0.002 \\
\hline Suprailiac & $0 \cdot 8$ & $3 \cdot 8$ & 0.5 & $5 \cdot 0$ & 0.492 \\
\hline Subscapular & $1 \cdot 1$ & 3.5 & $-1 \cdot 3$ & $4 \cdot 8$ & $<0.0001$ \\
\hline Mid-thigh & $2 \cdot 1$ & $5 \cdot 0$ & 0.7 & $5 \cdot 7$ & 0.03 \\
\hline Percentage fat (\%) & $0 \cdot 7$ & $2 \cdot 4$ & -0.2 & $2 \cdot 9$ & 0.002 \\
\hline Fat mass $(\mathrm{kg})$ & $1 \cdot 2$ & $2 \cdot 4$ & $0 \cdot 2$ & $3 \cdot 2$ & 0.002 \\
\hline Lean body mass $(\mathrm{kg})$ & $1 \cdot 8$ & $2 \cdot 0$ & $1 . \overline{5}$ & $1 \cdot 7$ & $0 \cdot 187$ \\
\hline
\end{tabular}

intake was 10623 (sD 3130) kJ (2539 (sD 748) kcal), while older women reported intake of 10435 (sD 2632) kJ (2494 (sD 629) $\mathrm{kcal}$ ). Both groups reported a similar percentage of energy from protein (adolescent girls, $13 \cdot 3$ (sD 2.3) \%; older women, 13.5 (SD 1.8) \%), carbohydrate (adolescent girls, 61.1 (SD 5.7) \%; older women, 60.9 (SD 6.1) \%) and fat (adolescent girls, 29.5 (SD 4.2) \%; older women, $29 \cdot 5$ (SD $4 \cdot 7) \%$ ). Energy and macronutrient intakes were within the Dietary Allowances for the Caribbean recommendations ${ }^{(18)}$.

Similar proportions of both groups developed complications of pregnancy. Three adolescents developed hypertension in pregnancy and five developed pre-eclampsia; among the older group, four women developed hypertension in pregnancy and twelve had pre-eclampsia. These differences were not statistically significant.

Assessments of infants at 6 weeks showed no significant differences in anthropometry between the two groups. Almost one-half of the adolescent girls (48.7\%) and just over half of the older women $(53 \cdot 0 \%)$ reported exclusive breast-feeding at 6 weeks postpartum $(P=$ $0 \cdot 44)$. Breast-feeding had no influence on weight at 6 weeks postpartum (data not shown).

\section{Discussion}

The present paper reports on postnatal weight retention in adolescent and older pregnant women and the component of weight associated with this weight retention. Adolescents retained more weight postnatally than older women despite their lower absolute values at the first antenatal and the 6 -week postpartum visits. Adolescents retained significantly higher percentage body fat and fat mass than their older counterparts but had similar lean body mass postnatally.

Both groups received similar exposures to health care. Adolescents and older women had eight or nine clinic visits during the study period, thus removing suggestions of treatment bias such as better nutritional counselling in one group. The educational and occupation status of women in this cohort, which were used to create the socio-economic score, were similar to Jamaica's national figures. These demographic characteristics suggest that our findings could be generalized to the population. We used the equations of Durnin and Rahaman and Siri to assess changes in body fat in the present study. The capacity 
of these equations to assess body fat in pregnancy has limitations, but they have been used previously to produce valid estimates of body composition during reproduction ${ }^{(19,20)}$

Adolescent pregnancy in Jamaica, as elsewhere, is a major health concern. Jamaica still has one of the highest incidences of adolescent pregnancy in the Caribbean. The birth rate for 15- to 19-year-olds was 108 births per 1000 women in the $1990 \mathrm{~s}^{(21)}$ and despite decreasing to 65 births per 1000 women in the period $2002-5^{(22)}$, is still high. In Jamaica, $40 \%$ of women less than 20 years old have had at least one pregnancy ${ }^{(23)}$.

Age at first pregnancy has been cited as an important risk factor for obesity ${ }^{(24)}$. The association between age at first pregnancy and weight retention has not been consistent in the literature. Gunderson et al. showed that an interval of less than 8 years between age at menarche and age at first pregnancy is a predictor for the development of postpartum obesity ${ }^{(25)}$. Similar results were reported by Kac et al., who showed that women who gave birth for the first time before age 23 years had $2 \cdot 8$ times greater risk of retaining $7.5 \mathrm{~kg}$ or more during the postpartum per$\operatorname{iod}^{(26)}$. In the present study, the age at menarche was significantly lower in the adolescent group compared with the older group of women $(12.5$ and $13 \cdot 1$ years, respectively; $P<0 \cdot 0001)$ and the adolescent girls had a shorter interval between menarche and pregnancy (approximately 5 years). The present findings are consistent with other studies showing that short spacing between menarche and pregnancy increases the risk of excess weight gain in the postpartum period. If indeed the adolescents are at a higher risk of weight retention after pregnancy, which in turn is a risk for obesity in later life, the higher incidence of adolescent pregnancies in Jamaica may contribute to the increasing prevalence of obesity in women. It is also reasonable to assume that adolescents who are starting their reproductive lives at an earlier age are predisposed to higher parity and hence the likelihood to gain excess weight at an earlier age. If pregnancy is a model for weight cycling which is associated with an increased risk of metabolic disease and obesity, then it can be concluded that teenagers are at greater risk for chronic adult disease.

It may be argued that growth continues in adolescence and increases in weight may reflect overall growth. In our study, the component of weight that was retained postpartum was fat mass and not lean mass. The reason for this increase in weight and fat mass in the adolescents is not clear. However, it is of interest to note that the findings are consistent with the animal model which showed that growing pregnant rats retained a greater proportion of gestational weight at 4-6 weeks after birth ${ }^{(27)}$. Elevated gestational weight gain has been cited as the most important factor contributing to increased weight retention $^{(28-31)}$. This increased weight gain was also seen in the current study, with the adolescents retaining more weight than the older women. An increase in gestational weight gain has been previously reported among adolescents and suggests that attainment of adequate weight and lean body mass in pregnancy impacts positively on birth size $\mathrm{e}^{(29,32,33)}$.

The dietary intakes of the adolescent girls and older women were similar and may not account for the difference observed in weight retention postpartum. Ohlin and Rossner showed that postpartum weight retention was more affected by change in lifestyle during pregnancy and more so after pregnancy ${ }^{(34)}$.

In conclusion, the current study demonstrates that adolescent girls had greater weight retention than older women in the postnatal period, which was predominantly fat mass. Our findings suggest that adolescents may be at greater risk for the development of obesity in later life, which may contribute to the increasing incidence of obesity in this population. Strategies should be developed to address this important public health issue.

\section{Acknowledgements}

The study was supported by a grant from the Caribbean Medical Research Council (Grant Number 05/03). There is no conflict of interest. All authors have contributed substantially to the present manuscript. M.M.T. conceived and designed the study, and conducted the measurements together with I.P.M. C.O. was the statistician who refined the statistical analyses. M.D.J. and M.G.A. together with the other authors contributed to the writing of the manuscript.

\section{References}

1. Gore SA, Brown DM \& West DS (2003) The role of postpartum weight retention in obesity among women: a review of the evidence. Ann Behav Med 26, 149-159.

2. Landon MB, Osei K, Platt M, O'Dorisio T, Samuels P \& Gabbe SG (1994) The differential effects of body fat distribution on insulin and glucose metabolism during pregnancy. Am J Obstet Gynecol 171, 875-884.

3. Segel JS \& McAnarney ER (1994) Adolescent pregnancy and subsequent obesity in African-American girls. J Adolesc Health 15, 491-494.

4. Kac G, Benício MHDA, Velásquez-Meléndez G, Valente JG \& Struchiner CJ (2004) Gestational weight gain and prepregnancy weight influence postpartum weight retention in a cohort of Brazilian women. J Nutr 134, 661-666.

5. Hediger ML, Scholl TO \& Schall JI (1997) Implications of the Camden Study of adolescent pregnancy: interactions among maternal growth, nutritional status, and body composition. Ann N Y Acad Sci 817, 281-291.

6. Rossner S (1992) Pregnancy, weight cycling and weight gain. Int J Obes Relat Metab Disord 16, 145-147.

7. Rodin J, Radke-Sharpe N, Rebuffe-Scrive M \& Greenwood MR (1990) Weight cycling and fat distribution. Int J Obes 14, 303-310.

8. Lissner L, Odell R \& D'Agostino R (1988) Health implications of weight cycling in the Framingham population. $A m$ $J$ Epidemiol 128, 1180-1184.

9. Brown JE, Kaye SA \& Folsom AR (1992) Parity-related weight change in women. Int J Obes Relat Metab Disord 16, 627-631. 
10. Rookus MA, Rokebrand P, Burema J \& Deurenberg P (1987) The effect of pregnancy on the body index 9 months postpartum in 49 women. Int J Obes 11, 609-618.

11. Newcombe RG (1982) Development of obesity in parous women. J Epidemiol Community Health 36, 306-309.

12. Garn SM, Shaw HA \& McCabe KD (1978) Effect of maternal smoking on weight and weight gain between pregnancies. Am J Clin Nutr 31, 1302-1303.

13. Billewicz WZ \& Thompson AM (1970) Body weight in parous women. Br J Prev Soc Med 24, 97-104.

14. Anon. (2000) Report of the National High Blood Pressure Education Program Working Group on High Blood Pressure in Pregnancy. Am J Obstet Gynecol 183, S1-S22.

15. Jackson M, Walker S, Cade J, Forrester T, Cruickshank JK \& Wilks R (2001) Reproducibility and validity of a quantitative food-frequency questionnaire among Jamaicans of African origin. Public Health Nutr 4, 971-980.

16. Siri WE (1961) Body composition from fluid spaces and density: analysis of methods. In Techniques for Measuring Body Composition, pp. 223-244 [ J Brozek and A Henschel, editors]. Washington, DC: National Academy of Sciences, National Research Council.

17. Durnin JVGA \& Rahaman MM (1967) The assessment of the amount of fat in the human body from measurements of skinfold thickness. Br J Nutr 21, 681-689.

18. Caribbean Food and Nutrition Institute (1994) Recommended Dietary Allowance for the Caribbean (Revised 1993). Kingston: CFNI.

19. Forsum E, Sadurskis A \& Wager J (1989) Estimation of body fat in healthy Swedish women during pregnancy and lactation. Am J Clin Nutr 50, 465-473.

20. van Raaij JMA, Schonk CM, Vermaat-Miedema SH, Peek ME \& Hautvast JG (1989) Body fat mass and basal metabolic rate in Dutch women before, during, and after pregnancy: a reappraisal of energy cost of pregnancy. Am J Clin Nutr 49, 765-772.

21. Morris L (1993) Contraceptive Prevalence Survey, Jamaica. Sexual Behaviour and Contraceptive Use among Young Adults, vol. IV. Atlanta, GA: US Department of Health and Human Services, Public Health Service, Centres for Disease Control and Prevention.
22. Statistical Institute of Jamaica (STATIN) Survey of Living Conditions (2007) and Demographic Statistics (2001-2006). Kingston: STATIN.

23. Jackson J, Eggleston E, Lee A \& Hardee K (1997) Reproductive knowledge, attitudes and behaviour among young adolescents in Jamaica. Soc Econ Stud 46, 95-109.

24. Herman AA \& Yu KF (1997) Adolescent age at first pregnancy and subsequent obesity. Paediatr Perinat Epidemiol 11, 20-41.

25. Gunderson EP, Abrams B \& Selvin S (2000) The relative importance of gestational gain and maternal characteristics associated with the risk of becoming overweight after pregnancy. Int J Obes Relat Metab Disord 24, 1660-1668.

26. Kac G, Benicio MHDA, Velasquez-Melendez G \& Valente JG (2003) Nine months postpartum weight retention predictors for Brazilian women. Public Health Nutr 7, 621-628.

27. Hashizume K, Ohashi K \& Hamajima F (1991) Adolescent pregnancy and growth in rats. Physiol Behav 49, 367-371.

28. Keppel KG \& Taffy SM (1993) Pregnancy-related weight gain and retention: implications of the 1990 Institute of Medicine guidelines. Am J Public Health 83, 1100-1103.

29. Lederman SA (1993) The effect of pregnancy weight gain on later obesity. Obstet Gynecol 82, 148-155.

30. Muscati SK, Gray-Donald K \& Koski KG (1996) Timing of weight gain during pregnancy: promoting fetal growth and minimizing maternal weight retention. Int $J$ Obes Relat Metab Disord 20, 526-532.

31. Abrams B, Selvin S \& Gunderson EP (2000) Pregnancy weight gain: still controversial. Am J Clin Nutr 71, 1233S-1241S.

32. Thame M, Osmond $\mathrm{C}$, Trotman $\mathrm{H}$, Fletcher $\mathrm{H}$ \& Antoine $\mathrm{M}$ (2007) Body composition in pregnancies of adolescents and older women and the relationship to birth anthropometry. Eur J Clin Nutr 61, 47-53.

33. Scholl TO, Hediger ML, Schall JI, Ances IG \& Smith WK (1995) Gestational weight gain, pregnancy outcome, and postpartum weight retention. Obstet Gynecol 86, 423-427.

34. Ohlin A \& Rossner S (1994) Trends in eating patterns, physical activity and sociodemographic factors in relation to postpartum body weight development. Br J Nutr 71, 457-470. 